\title{
WPEYW WIRTUALNEJ RZECZYWISTOŚCI NA POZIOM DYSTRAKCJI OD BODŹCów BóLOWYCH
}

\author{
Jakub Szarpak \\ Instytut Psychologii Uniwersytetu Wrocławskiego \\ ul. J. Wł. Dawida 1, 50-527 Wrocław \\ E-mail: 290978@uwr.edu.pl \\ ORCID: https://orcid.org/0000-0002-7057-5024 \\ Justyna Bidzińska \\ Instytut Psychologii Uniwersytetu Wrocławskiego \\ ul. J. Wł. Dawida 1, 50-527 Wrocław \\ E-mail: 290317@uwr.edu.pl \\ ORCID: https://orcid.org/0000-0001-7855-8491
}

\begin{abstract}
Abstrakt
Cel badań. Badanie skuteczności rodzaju dystrakcji od bodźców bólowych polegającej na wykorzystaniu wirtualnej rzeczywistości.

Materiały i metody. Grupę badanych wprowadzano za pomocą gogli wirtualnej rzeczywistości w warunek dystrakcji pobudzającej, relaksującej, oraz w warunek kontrolny. Ból wywoływany był poprzez zanurzenie ręki w zimnej wodzie. Skuteczność dystrakcji mierzona była za pomocą deklarowanego poziomu odczuwanego bólu, zaznaczonego na skali VAS, oraz czasu, przez który badany wytrzymywał działanie bodźca bólowego. Na koniec wyniki porównano z testem temperamentu PTS.

Rezultaty. Badani istotnie dłużej znosili działanie bodźca bólowego w warunkach dystrakcji, niż w warunku kontrolnym; lecz nie stwierdzono istotnej różnicy pomiędzy warunkiem pobudzającym a warunkiem relaksującym. Żaden z warunków eksperymentu nie miał wpływu na deklarowany poziom odczuwanego bólu. Wykryto dodatnią korelację wyników uzyskanych w skali Siły Procesu Hamowania kwestionariusza PTS z czasem wytrzymywania bodźca bólowego we wszystkich trzech warunkach eksperymentu.

Słowa kluczowe: wirtualna rzeczywistość, ból, dystrakcja, napięcie, relaksacja, cold-pressor, VR
\end{abstract}

The impact of virtual reality on distraction level from pain stimuli

Abstract

Aim of the study: Testing the effectiveness of three pain stimuli distraction types based on the use of virtual reality.

Materials and Methods: A group of students, using virtual reality goggles, was exposed to stimulating and relaxing distractions, as well as a control condition. Pain was 
induced by submerging the student's arm in freezing water. The effectiveness of the distraction was measured with the help of the declared level of pain felt, marked on the VAS scale, as well as the time during which the student could resist the pain stimulus. At the end, the measurements were compared to the results of the PTS temperament survey.

Results: Participants withstood the pain stimulus significantly longer in the distraction condition than in the control condition. However, no significant differences were found between the stimulating and the relaxing conditions. None of the conditions had any influence on the reported level of pain. A significant, positive correlation between PTS' Strength of Inhibition subscale result and the time of withstanding the pain stimulus was found in all three conditions of the experiment.

Key words: virtual reality, pain, distraction, tension, relaxation, cold-pressor, VR

\section{WPROWADZENIE}

Od wieków poszukiwano sposobów pozwalających zmniejszyć intensywność odczuwanego chronicznego i krótkotrwałego bólu fizycznego. Z biegiem czasu dzięki licznym badaniom odkrywano coraz więcej skutecznych metod. Wiele technik dystrakcyjnych było z powodzeniem używanych do minimalizowania odczucia bólu i innych dolegliwości (Stinson i in., 2008).

Ostatnie badania pokazują że nowa forma dystrakcji - wykorzystująca wirtualną rzeczywistość - może być również z powodzeniem używana do odwracania uwagi od odczuwania bólu eksperymentalnego i klinicznego, zarówno u dzieci, jak i u dorosłych (Malloy i Milling, 2008; Kenney i Milling, 2010; Wiederhold i Wiederhold, 2007; Dahlquist i in.,2009; Hoffman i in., 2000; Dahlquist i in., 2007; Gold i in., 2006). $\mathrm{W}$ takich typach dystrakcji, badany wchodzi $\mathrm{w}$ interakcję z komputerowo wygenerowanym środowiskiem poprzez gogle wirtualnej rzeczywistości, które wytwarzają odpowiednie bodźce słuchowe i wzrokowe, jednocześnie odcinając jednostkę od bodźców ze świata zewnętrznego.

Przeprowadzono wiele badań, w których analizowano, który z aspektów dystrakcji związanej z wirtualną rzeczywistością najbardziej przyczynia się do jej efektywności. Stwierdzono, że aktywna dystrakcja (granie w grę) jest istotnie skuteczniejsza niż pasywna dystrakcja (oglądanie jak ktoś inny gra w grę) (Dahlquist i in., 2007). Wiadomo też, że na skuteczność dystrakcji wpływa jakość i nowoczesność gogli wirtualnej rzeczywistości (Wender i in.,2009). Badano także czy rodzaj dystrakcji ma wpływ na jej skuteczność. Jednym z przykładów może być artykuł, w którym nie stwierdzono różnicy w skuteczności pomiędzy dystrakcją przy użyciu zimnego i ciepłego środowiska wirtualnego (Mühlberger i in., 2007). Nie wykazano również związku pomiędzy skutecznością dystrakcji, a punktem patrzenia wirtualnego awatara (Dahlquist i in., 2010). Wykazano również, że czynnikiem, który w dużym stopniu - 12\%, wyjaśnia sposób reakcji na ból wśród dzieci jest temperament (Young i Fu., 1988), oraz że kobiety wykazują niższy próg bólu i niższą tolerancję na ból chroniczny (Fillingim i in., 2003).

Zdecydowaliśmy się przeprowadzić własne badania, sprawdzające czy rodzaj dystrakcji ma wpływ na jej skuteczność. Problem ten jest ważny w kontekście odwracania uwagi od silnego bólu, gdzie możliwe stałoby się zwiększenie siły dystrakcji, przez co 
odczucie bólu mogłoby zostać zminimalizowane w dużo większym stopniu. Porównane zostały dwa rodzaje dystrakcji - wprowadzająca osobę badaną w stan pobudzenia oraz w stan relaksacji. Jako hipotezy przyjęte zostały założenia, że zarówno warunek pobudzający, jak i relaksujący będą istotnie odwracać uwagę od bodźca bólowego (hipoteza 1) - zmniejszać deklarowany przez badanych poziom bólu oraz zwiększać czas wytrzymywania przez nich bodźca bólowego - oraz, że warunek pobudzający będzie skuteczniej od relaksującego odwracać uwagę od bodźca bólowego, gdyż będzie bardziej aktywnym typem dystrakcji (poprzez wystąpienie pobudzenia) dla osoby badanej (hipoteza 2). Ponadto, założyliśmy, że osoby z wysokim wynikiem w skali Siła Procesów Hamowania uzyskanym w kwestionariuszu temperamentu PTS będą istotnie dłużej znosić działanie bodźca bólowego (hipoteza 3). Takie przewidywanie oparte jest na fakcie, że osoby z wysokim wynikiem w tej skali charakteryzują się wzmożoną kontrolą zachowania, posiadają łatwość w powstrzymywaniu się od zachowań niezgodnych z oczekiwaniami oraz nie ujawniają swoich emocji, jeśli nie jest to pożądane. Przyjęliśmy również założenie, że kobiety - podobnie jak w przypadku bólu chronicznego, charakteryzować się będą niższą wytrzymałością na ekspozycję bodźca bólowego oraz wyższą siłą odczuwanego bólu, niż mężczyźni (hipoteza 4).

\section{MATERIAEY I METODY}

\section{Osoby badane}

W badaniu wzięło udział $N=16$ studentów w wieku 20-32 lat $(M=22,19, S D=2,9)$, studiujących na wrocławskich uczelniach wyższych (Uniwersytet Wrocławski, Politechnika Wrocławska, Uniwersytet Medyczny im Piastów Śląskich), 43,75\% stanowiły kobiety, a 56,25\% mężczyźni.

\section{Sprzęt badawczy}

Cold-pressor test - w którym znajdowała się woda o temperaturze 0,5-1 stopnia Celsjusza, wprawiana w ruch za pomocą cyrkulatora. Woda sprowadzana była do odpowiedniej temperatury za pomocą kostek lodu. Temperatura wody mierzona była za pomocą termometru elektronicznego.

Gogle wirtualnej rzeczywistości - Samsung Gear VR Oculus SM-R323 VR2, połączone $\mathrm{z}$ telefonem Samsung Galaxy S8 Plus.

Aplikacje - Uczestnikom wyświetlane były odpowiednie aplikacje: Epic Roller Coaster - wyświetlana w środowisku napięcia (E2) Forest of Serenity - wyświetlana w środowisku relaksującym (E3). W środowisku kontrolnym (E1) uczestnikom nie wyświetlała się żadna aplikacja, jedynie czarne tło.

\section{Metody badawcze}

Metryczka - zawierała takie dane jak: płeć, wiek, dominująca ręka, miejsce zamieszkania, aktualna sytuacja zawodowa.

Kwestionariusz temperamentu PTS (Strelau, Zawadzki, 1998) - kwestionariusz służący do diagnozy temperamentu rozumianego zgodnie z koncepcją Pawłowa. Narzędzie oparte jest na trzech podstawowych skalach: Siły Procesu Pobudzenia (SPP), Siły Procesu Hamowania (SPH) i Ruchliwości Procesów Nerwowych (RPP). Określa się 
także równowagę procesów nerwowych będącą stosunkiem SPP do SPH. Kwestionariusz składa się z 57 twierdzeń z czterostopniową skalą odpowiedzi.

\section{Wskaźniki bólu}

Skala VAS - wizualna skala analogowa o długości 12,4 cm służąca do zaznaczenia przez osobę biorącą udział w eksperymencie poziomu odczuwanego podczas badania bólu.

Wskaźnik behawioralny - czas mierzony stoperem od momentu włożenia dłoni osoby badanej do zimnej wody do jej wyciągnięcia.

\section{Procedura badania}

Eksperyment został przeprowadzony we Wrocławiu, we wcześniej przygotowanym do tego pomieszczeniu. Każda osoba biorąca udział w eksperymencie była umówiona na określoną godzinę. Po dotarciu na miejsce uczestnik wypełniał metryczkę. Do pomieszczenia osoby badane były wprowadzane pojedynczo, tak, aby ewentualna obecność innych uczestników nie wpłynęła na ich wyniki.

Odczytując dane z ankiety sprawdzane było na początku to, która ręka jest dominująca u osoby badanej. Biorąc pod uwagę informacje z metryczki, każdy uczestnik badania proszony był o zanurzenie w wodzie swojej niedominującej dłoni (wszyscy uczestnicy badania byli praworęczni, więc prosiliśmy ich za każdym razem o zanurzenie lewej ręki).

Przed przystapieniem do badania eksperymentator czytał uczestnikowi krótką instrukcję: „Proszę teraz założyć gogle VR i słuchawki. Gdy będzie Pan/Pani gotowy/a, proszę powiedzieć, a ja włożę Panu/Pani rękę do zimnej wody. Kiedy odczuwany dyskomfort stanie się trudny do zniesienia, proszę wyciągnąc dłoń z wody". Eksperymentator przy użyciu stopera mierzył czas od momentu włożenia ręki badanego do zimnej wody, aż do jej wyciagnięcia. Po wyjęciu ręki z wody osoba badana otrzymywała ręcznik papierowy, którym mogła ją wytrzeć.

Po każdym warunku eksperymentu osoby badane były proszone o zaznaczenie na skali VAS poziomu odczuwanego podczas badania bólu. Przerwy między warunkami eksperymentalnymi trwały po 10 minut, tak aby dłoń mogła się w tym czasie ogrzać. Po ostatnim z nich uczestnicy wypełniali kwestionariusz temperamentu PTS.

Eksperyment został przeprowadzony w trzech warunkach. Kolejność ich wystąpienia u każdej osoby badanej była ustalana losowo, poprzez rotację. Pierwszym z nich była próba kontrolna, kiedy osoba badana zakładała gogle VR bez uruchomienia żadnej aplikacji (widoczne było czarne tło) oraz słuchawki (E1). Drugim warunkiem eksperymentalnym było nałożenie słuchawek i gogli z uruchomioną aplikacją Epic Roller Coaster (E2) - warunek pobudzający, a trzecim - z aplikacją Forest of Serenity (E3) - warunek relaksujący.

\section{WYNIKI BADAŃ \\ Statystyka}

Analizy statystyczne zostały przeprowadzone z wykorzystaniem programu Statistica. W pierwszej kolejności określono normalność rozkładu dla zmiennych. 
Rozkład subiektywnego odczucia bólu posiadał cechy rozkładu normalnego zarówno w pierwszym warunku eksperymentalnym $(W=0.96, p=0.64)$, jak i $\mathrm{W}$ drugim $(W=0.97, p=0.86)$ oraz trzecim $(W=0.93, p=0.25)$. $Z$ kolei dla czasu ekspozycji bodźca bólowego nie wykazano cech rozkładu normalnego w pierwszym $(W=0.74, p=$ $0.001)$, drugim $(W=0.81, p=0.003)$ oraz trzecim warunku $(W=0.85, p=0.02)$

W związku z takimi wynikami, wykorzystano statystyki parametryczne (ANOVA Friedmana, test T Studenta, korelacja Pearsona) oraz nieparametryczne (test kolejności par Wilcoxona, test U Manna Whitneya).

Wpływ warunku eksperymentalnego na behawioralny wskaźnik bólu

W pierwszej kolejności postanowiono zbadać czy warunek eksperymentalny wpływa na behawioralny wskaźnik bólu (czas zanurzenia ręki w zimnej wodzie). W tym celu przeprowadzono analizę ANOVA Friedmana, która wykazała różnice istotne statystycznie $(F(2)=12,04 ; N=16 ; p<0,01)$ pomiędzy czasami wytrzymywania bólu przez badanych w każdym warunku.

W następnej kolejności porównano, które z warunków eksperymentalnych różnią się między sobą. Test kolejności par Wilcoxona wykazał istotne statystycznie $(Z=2,2$; $p<0,05)$ różnice $\mathrm{w}$ czasie wytrzymywania bodźca bólowego pomiędzy warunkami kontrolnym i pobudzającym. Osoby badane dłużej trzymały rękę w zimnej wodzie $\mathrm{w}$ warunku pobudzającym. Okazało się również, że istnieją istotne statystycznie $(Z=$ $2,83 ; p=0,0047)$ różnice pomiędzy warunkami kontrolnym i relaksującym. Czas trzymania dłoni w zimnej wodzie był dłuższy w warunku relaksującym. Różnice w czasie wytrzymywania bodźca bólowego pomiędzy warunkami relaksującym oraz pobudzającym nie były istotne statystycznie $(Z=1,3 ; p=0,2)$. Oznacza to, że zgodnie z hipotezą dystrakcja w warunkach pobudzającym i relaksacyjnym sprawiła, że badani trzymali rękę dłużej niż w warunku kontrolnym. Nie stwierdzono jednak różnicy istotnej statystycznie pomiędzy warunkiem pobudzającym i relaksacyjnym. Zatem hipoteza 2 nie została potwierdzona. Wartości średnich i odchyleń standardowych znajdują się w Tabeli 1.

Tabela 1. Średnie i odchylenia standardowe dla czasu zanurzenia dłoni w zimnej wodzie i deklarowanego poziomu odczucia bólu

\begin{tabular}{lccccc}
\hline $\begin{array}{l}\text { Czas zanurzenia dłoni w zimnej wodzie } \\
\text {-behawioralny wskaźnik }\end{array}$ & M & \multicolumn{3}{c}{$\begin{array}{l}\text { Skala VAS - subiektywny } \\
\text { wskaźnik }\end{array}$} \\
\hline \multicolumn{1}{l}{$\begin{array}{l}\text { Warunek kontrolny - } \\
\text { bez dystrakcji }\end{array}$} & 78,13 & 69,13 & & 7,57 & SD \\
\hline $\begin{array}{l}\text { Pobudzajace } \\
\text { środowisko wirtualne }\end{array}$ & 105,69 & 77,25 & & 7,03 & 2,74 \\
\hline $\begin{array}{l}\text { Relaksujące } \\
\text { środowisko wirtualne }\end{array}$ & 117,31 & 70,14 & & 8,05 & 2,53 \\
\hline
\end{tabular}

Wpływ warunku eksperymentalnego na subiektywne odczuwanie bólu

W dalszej kolejności postanowiono sprawdzić czy warunek eksperymentalny ma wpływ na subiektywne odczucie bólu zaznaczane na skali VAS. W tym celu przepro- 
wadzono analizę ANOVA Friedmana. Nie wykazano różnic istotnych statystycznie $(F(2,30)=1.65 ; p=0,21)$ pomiędzy subiektywnymi odczuciami bólu zaznaczonymi przez badanych na skali VAS, w warunku kontrolnym, pobudzającym oraz relaksującym. Wartości średnich i odchyleń standardowych znajdują się w Tabeli 1.

Następnie, przeprowadzając test T studenta, nie wykryto różnic istotnych statystycznie w zaznaczanym odczuciu bólu pomiędzy warunkiem kontrolnym i pobudzającym $(t=0,94 ; d f=15 ; p=0,36)$, pomiędzy warunkiem kontrolnym i relaksującym $(t$ $=0,96 ; d f=15 ; p=0,35)$ oraz pomiędzy warunkiem pobudzającym i relaksującym $(t=1,67$; $\mathrm{df}=15 ; p=0,12$ ).

Powyższe rezultaty oznaczają że rodzaj warunku eksperymentalnego nie ma wpływu na subiektywne odczucie bólu przez badanych.

\section{Pteć a deklarowany poziom bólu}

Postanowiono sprawdzić, czy kobiety i mężczyźni w badanej grupie różnią się pod względem deklarowanego poziomu bólu. Test $\mathrm{T}$ wykazał różnice istotne statystycznie $(t(14)=2,47 ; p<0,05)$ tylko $\mathrm{w}$ warunku pobudzającym, $\mathrm{w}$ którym to kobiety zaznaczały niższy poziom bólu $(M=5,68 ; S D=2,31)$ niż mężczyźni $(M=8,76 ; S D=$ $2,69)$. W warunku kontrolnym nie było różnic istotnych statystycznie $(t(14)=0,1 ; p>$ $0,05)$ pomiędzy deklarowanym poziomem bólu przez kobiety $(M=7,5 ; S D=3,02)$ oraz mężczyzn $(M=7,64 ; S D=2,56)$. Nie wykazano różnic istotnych statystycznie $(t(14)=$ $0,38 ; p>0,05)$ również $\mathrm{w}$ warunku relaksującym pomiędzy deklarowanym poziomem bólu u kobiet $(M=7,83 ; S D=2,47)$ i mężczyzn $(M=8,33 ; S D=2,76)$.

\section{Pteć a czas ekspozycji bodźca bólowego}

W celu sprawdzenia czy kobiety i mężczyźni w badanej grupie różnią się pod względem czasu ekspozycji bodźca bólowego przeprowadzono analizę testem U Manna Whitneya. Wykazał on, że kobiety $(M=143,22 ; S D=84,67)$ nie różnią się istotnie statystycznie ( $\mathrm{U}=17 ; \mathrm{Z}=1,48 ; p=0,14)$ od mężczyzn $(M=57,43 ; S D=23,04)$ $\mathrm{W}$ warunku pobudzającym oraz istotnie statystycznie $(U=16 ; Z=1,60 ; p=0,11)$ dłużej trzymały rękę w zimnej wodzie w warunku relaksacyjnym $(M=147,78 ; S D=72,94)$ niż mężczyźni $(M=78,14 ; S D=45)$. Różnica w warunku kontrolnym pomiędzy kobie$\operatorname{tami}(M=106,44 ; S D=79,23)$ a mężczyznami $(M=41,71 ; S D=28,77)$ znajdowała się na granicy istotności statystycznej $(U=14 ; Z=1,8 ; p=0,07)$

\section{Typ temperamentu, a czas ekspozycji bodźca bólowego}

W dalszej kolejności przeprowadzono analizę korelacji. Macierze korelacji wykazały istotny statystycznie związek $(p<0,05 ; N=16)$ pomiędzy wynikiem uzyskanym w skali Siły Procesu Hamowania w kwestionariuszu PTS, a czasem wytrzymywania bodźca bólowego $\mathrm{W}$ warunku kontrolnym $(r=0,51)$, pobudzającym $(r=0,52)$ i relaksacyjnym $(r=0,55)$. Oznacza to, że im wyższy wynik uzyskała osoba w skali Siły Procesu Hamowania, tym dłużej znosiła ona działanie bodźca bólowego. Nie uzyskano natomiast istotnych korelacji między pozostałymi wymiarami temperamentu, a czasem trzymania ręki w zimnej wodzie.

Nie wykazano również istotnych korelacji pomiędzy deklarowanym odczuciem bólu, a wymiarami temperamentu PTT Strelaua. Wyniki przedstawia Tabela 2. Należy 
jednak zwrócić uwagę na fakt, że korelacja pomiędzy Siłą Procesów Hamowania, a deklarowaną siłą odczuwanego bólu $\mathrm{w}$ warunku pobudzającym jest stosunkowo silna ( $r=$ $-0.42 ; p=0.11$, natomiast nie jest istotna przy przyjętym poziomie istotności statystycznej $p=0.05$. Może wynikać to z ograniczeń badania, opisanych w Interpretacji wyników.

Tabela 2. Wartości korelacji pomiędzy wymiarami temperamentu PTT Strelaua, a deklarowanym odczuciem bólu

\begin{tabular}{ccccc}
\hline & $\begin{array}{c}\text { Siła Procesów } \\
\text { Pobudzenia }\end{array}$ & $\begin{array}{c}\text { Siła Procesów } \\
\text { Hamowania }\end{array}$ & $\begin{array}{c}\text { Ruchliwość } \\
\text { Procesów } \\
\text { Nerwowych }\end{array}$ & $\begin{array}{c}\text { Równowaga } \\
\text { Procesów } \\
\text { Nerwowych }\end{array}$ \\
\hline VAS 1 & 0,16 & $R$ & & \\
\hline VAS 2 & $-0,23$ & $-0,2$ & 0,1 & 0,13 \\
\hline VAS 3 & $-0,02$ & $-0,42$ & $-0,18$ & $-0,15$ \\
\hline
\end{tabular}

\section{INTERPRETACJA WYNIKÓW}

W badaniu potwierdzona została hipoteza o skuteczności użycia wirtualnej rzeczywistości do zmniejszania siły odczuwanego bólu. Początkowo zakładaliśmy również, że skuteczniejszym rodzajem dystrakcji od bodźców bólowych będzie środowisko wirtualne, które wprowadzi osobę badaną w stan pobudzenia. Nasze przypuszczenia w tej kwestii nie potwierdziły się. Różnice w czasie wytrzymywania bodźca bólowego pomiędzy warunkami relaksującym oraz pobudzającym nie były istotne statystycznie. Rodzaj zastosowanej dystrakcji nie miał więc znaczenia dla czasu przez jaki osoby badane trzymały dłoń w zimnej wodzie.

Analizastatystyczna wykazała, że rodzaj warunku eksperymentalnegoniewpływał nasubiektywneodczuciebólu przezuczestnikóweksperymentu.W porównaniachmiędzypłciowych okazało się, że kobiety deklarowały niższy poziom odczuwanego bólu niż mężczyźni, jednak tylkow warunku pobudzającym. Kobiety trzymały takżeistotnie statystycznie dłużej niż mężczyźni rękę w zimnej wodzie w warunkach pobudzającym i relaksującym, co nie potwierdziło hipotezy o tym, iż kobiety charakteryzują się niższą wytrzymałością na ekspozycję bodźca bólowego oraz wyższą siłą odczuwanego bólu, niż mężczyźni.

Ważnym aspektem naszego eksperymentu było także sprawdzenie występowania zależności między wynikami osób badanych uzyskanymi w eksperymencie i w poszczególnych skalach kwestionariusza temperamentu PTS. Związek pomiędzy wynikiem uzyskanym w skali Siły Procesu Hamowania w kwestionariuszu PTS, a czasem wytrzymywania bodźca bólowego $\mathrm{w}$ warunku kontrolnym, pobudzającym i relaksacyjnym okazał się być dodatni oraz istotny statystycznie. Siła Procesu Hamowania przejawia się, na poziomie zachowania, w zdolności do odraczania lub powstrzymywania się od reakcji i zachowań wtedy, kiedy wymaga tego kontekst sytuacyjny. Duża siła procesu hamowania warunkowego ułatwia kontrolę zachowania (Strelau i Zawadzki, 1998). Im wyższy był wynik, jaki osoba badana uzyskała w skali Siły Procesu Hamowania, tym dłużej znosiła ona działanie bodźca bólowego, co potwierdziło przyjętą przez nas hipotezę. 
Pomimo dołożenia wszelkich starań, zdajemy sobie sprawę z pewnych metodologicznych niedociągnięć naszego eksperymentu. Dobrana przez nas próba badawcza nie jest reprezentatywna dla całej populacji. Jest stosunkowo niewielka i mało różnorodna, jeśli chodzi o wiek osób badanych, które wzięły udział w eksperymencie, co mogło zwiększyć prawdopodobieństwo błędnego nieodrzucenia hipotezy zerowej. Szczególnie wyraźne wydaje się to w przypadku korelacji między Siłą Procesów Hamowania, a deklarowanym poziomem odczuwanego bólu, która jest silna, lecz nieistotna; być może przy większej próbie związek okazałby się być istotny. Czynnikiem, który mógł zaburzyć wyniki badania były dobrane przez nas aplikacje. Ich czas trwania był ograniczony, a kilku uczestników trzymało rękę w wodzie aż do ich końca, kiedy prosiliśmy o wyciągnięcie dłoni z wody. Kolejnym aspektem, który w pewnym stopniu mógł wpłynąć na rezultaty eksperymentu była pora dnia, o której badaliśmy poszczególne osoby. Ze względu na czasochłonność badania, uczestnicy brali w nim udział o różnych godzinach, co mogło oddziaływać na poziom ich wrażliwości sensorycznej.

\section{Bibliografia}

[1] Dahlquist, L. M., McKenna, K. D., Jones, K. K., Dillinger, L., Weiss, K. E., \& Ackerman, C. S. (2007). Active and passive distraction using a head-mounted display helmet: effects on cold pressor pain in children. Health Psychology, 26(6), 794.

[2] Dahlquist, L. M., Weiss, K. E., Law, E. F., Sil, S., Herbert, L. J., Horn, S. B., ... \& Ackerman, C. S. (2009). Effects of videogame distraction and a virtual reality type head-mounted display helmet on cold pressor pain in young elementary school-aged children. Journal of Pediatric Psychology, 35(6), 617-625.

[3] Dahlquist, L. M., Herbert, L. J., Weiss, K. E., \& Jimeno, M. (2010). Virtual-reality distraction and cold-pressor pain tolerance: does avatar point of view matter?. Cyberpsychology, Behavior, and Social Networking, 13(5), 587-591.

[4] Fillingim, R. B., Doleys, D. M., Edwards, R. R., \& Lowery, D. (2003). Clinical characteristics of chronic back pain as a function of gender and oral opioid use. Spine, 28(2), 143-150.

[5] Gold, J. I., Kim, S. H., Kant, A. J., Joseph, M. H., \& Rizzo, A. S. (2006). Effectiveness of virtual reality for pediatric pain distraction during IV placement. CyberPsychology \& Behavior, 9(2), 207-212

[6] Hoffman, H. G., Patterson, D. R., \& Carrougher, G. J. (2000). Use of virtual reality for adjunctive treatment of adult burn pain during physical therapy: a controlled study. The Clinical Journal of Pain, 16(3), 244-250.

[7] Kenney, M. P., \& Milling, L. S. (2016). The effectiveness of virtual reality distraction for reducing pain: A meta-analysis. Psychology of Consciousness: Theory, Research, and Practice, 3(3), 199.

[8] Malloy, K. M., \& Milling, L. S. (2010). The effectiveness of virtual reality distraction for pain reduction: a systematic review. Clinical Psychology Review, 30(8), 1011-1018.

[9] Mühlberger, A., Wieser, M. J., Kenntner-Mabiala, R., Pauli, P., \& Wiederhold, B. K. (2007). Pain modulation during drives through cold and hot virtual environments. CyberPsychology \& Behavior, 10(4), 516-522.

[10] Stinson J., Yamada J,. Dickson A., Lamba J., i Stevens B. (2008). Review of systematic reviews on acute procedural pain in children in the hospital setting. Pain Research and Management, 13(1), 51-57.

[11] Strelau, J., Zawadzki, B. (1998). Kwestionariusz Temperamentu PTS podręcznik. Warszawa: Pracownia Testów Psychologicznych Polskiego Towarzystwa Psychologicznego.

[12] Wender, R., Hoffman, H. G., Hunner, H. H., Seibel, E. J., Patterson, D. R., \& Sharar, S. R. (2009). Interactivity influences the magnitude of virtual reality analgesia. Journal of Cyber Therapy and Rehabilitation, 2(1), 27.

[13] Wiederhold, M. D., \& Wiederhold, B. K. (2007). Virtual reality and interactive simulation for pain distraction. Pain Medicine, iss supl 3(8), 182-188.

[14] Young, M. R., \& Fu, V. R. (1988). Influence of play and temperament on the young child's response to pain. Children's Health Care, 16(3), 209-215. 